\title{
DESAIN ROBOT PEMBERI PAKAN AYAM TERNAK OTOMATIS BERBASIS MIKROKONTROLER ATMEGA16 MENGGUNAKAN SIMULATOR SOFTWARE PROTEUS 8
}

\author{
Rini Nuraini \\ Universitas Bunda Mulia, Prodi Teknik Informatika \\ neneng.rininuraini@yahoo.co.id
}

\begin{abstract}
Abstrak
Permasalahan mahalnya upah tenaga kerja saat ini Sudan sangat menjadi bahan pertimbangan untuk melakukan hal-hal pekerjaan yang rutin dikerjakan setiap hari, seperiti halnya memberi minum pada ternak, untuk kasus ini, perlu adanya solusi atas permasalahannya, yaitu dengan membuat suatu robot untuk mengerjakan hal tersebut. Robot Pemberi Pakan Ayam Ternak Otomatis atau yang selanjutkanya akan disingkat menjadi Robot PPATO, tujuannya untuk melakukan pekerjaan rutin memberi pakan pada ayam ternak sacara otomatis pada waktu tertentu yang terjadwal. Karakteristik Robot PPATO yaitu robot akan memberikan pakan pada waktu tertentu terjadwal, dengan bantuan komponen elektronika utama yaiut: IC Timer, Driver Motor DC, Sensor Infra Red atau LDR, dan buzzer yang dipasang pada mesin robot. Penelitian dimulai dengan menganalisis dan melakukan perancangan sistem balk hardware maupun software, kemudian dilanjutkan dengan melakukan coding pemrograman. Bahasa pemrograman yang dipakai adalah Bahasa $C$. Penelitian ini menggunakan alat IC Timer untuk waktu pemberian pakan. Tahap terakhir adalah uji coba sistem untuk mengetahui apakah sistem telah berjalan dengan baik sesuai yang direncanakan. Robot PPTAO akan memberikan pakan pada waktu yang telah ditentukan dan sensor LDR Sensor Infra Red atau LDR yang berfungsi mendeteksi pakan. Hasil penelitian didapatkan sebuah desain dari sebuah Robot PPTAO tersebut, yang dapat langsung disimulasikan dengan menggunakan Simulator Software Proteus 8.
\end{abstract}

Kata Kunci: IC Timer, ATMega 16, Robot Pemberi Pakan Ayam Ternak Otomatis, Sistem Otomatisasi, Simulator Software Proteus 8.

\section{Pendahuluan}

\subsection{Latar Belakang}

Permasalahan mahalnya upah tenaga kerja saat ini sudah sangat menjadi bahan pertimbangan untuk melakukan hal-hal pekerjaan yang rutin dikerjakan setiap hari, seperti halnya pemberian pakan pada ternak, untuk hal ini, perlu adanya solusi atas permasalahan ini, yaitu dengan membuat suatu robot untuk mengerjakan hal tersebut.

Arti robot itu sendiri berasal dari kata robota, yang berarti pekerja. Arti secara luas dari robot adalah sebuah alat mekanik yang dapat melakukan tugas fisik atau pekerjaan seperti halnya pekerja, baik menggunakan pengawasan dan kontrol manusia, atau menggunakan program yang telah didefinsikan atau diprogram terlebih dahulu pada IC Mikrokontroler. Sehingga pengganti pekerja rutin yang biasanya dilakukan oleh manusia dan diganti dengan sebuah robot, menurut penulis sudah sangat tepat, atas dasar hal tersebut, penulis mengangkat topik pada penelitian ini berupa desain sebuah robot pemberi pakan ayam ternak otomatis.

Robot Pemberi Pakan Ayam Ternak Otomatis atau yang selanjutkanya akan disingkat menjadi Robot PPTAO akan berjalan bekerja memberi pakan ternak secara otomatis pada waktu tertentu sesuai settingannya, dengan bantuan IC Timer, serta beberapa komponen elektronika lainnya.

\subsection{Rumusan Masalah}

Mengacu pada latar belakang tersebut, maka dapat di rumuskan beberapa permasalahan yang akan dibahas pada penelitian ini, yaitu: bagaimana perancangan dari desain skema serta mensimulasikan Robot PPTAO tersebut dengan menggunakan simulasi Software Proteus 8 ?

\subsection{Batasan Masalah}

Untuk membatasi cakupan penelitian supaya tidak terlalu luas, maka dapat dibuat ruang lingkupnya sebagai berikut: menggunakan simulasi Software Proteus 8 dengan bahasa pemrograman C.

\section{Landasan Teori}

Robot Line Follower Berbasis Mikrokontroler Atmega 16 dengan Menampilkan Status Gerak Pada LCD. Penelitian ini dilakukan oleh Achmad Zakki Falani dan Setyawan Budy pada tahun 2015. Penelitian ini bertujuan untuk membuat robot line follower yang dapat meringkankan pekerjaan manusia. Kesimpulan yang didapat dari penelitian tersebut yaitu:

a. Software Proteus sangat bermanfaat bagi para pemula yang ingin mempelajari tentang komponen elektronika.

b. Mikrokontroler ATmega32A dapat digunakan untuk membuat rangkaian sistem minimum karena fitur dan jumlah memory yang dimiliki ATmega32A.

Rancang Bangun Alat Penguras Dan Pengisi Tempat Minum Ternak Ayam Berbasis Mikrokontroler Atmega 16, dalam sistem ini yang menjadi pengendali adalah mikrokontroler ATMega 16, sistem ini akan menguras apabila sensor kejernihan telah mendeteksi air dalam wadah telah keruh, secara bersamaan sistem mengisi air pada wadah, pada saat air tidak mencapai batas ketinggian. Pada Jurnal Teknik Elektro dan 
Komputer. Ejournal.unsurat.aac.id. ISSN: $2301-$ 8402.

Kendali logika fuzzi digunakan agar pakan dapat terdistribusi secara merata disepanjang konveyor. Input dari model alat pemberi pakan ayam otomatis ini adalah strain gage yang digunakan untuk menimbang berat pakan, RTC DS1307 yang digunakan sebagai timer agar pakan dapat diberikan secara tepat waktu, dan rangkaian optocoupler digunakan untuk menghitung jarak konveyor. Dari hasil pengamatan, alat ini dapat memberikan pakan ternak secara otomatis, teratur, dan terjadwal sesuai dengan jumlah dan umur dari ternak. Pakan juga terdistribusi secara merata di sepanjang konveyor. Aji Ridhamuttaqin, pada Rancang Bangun Model Sistem Pemberi Pakan Ayam Otomatis Berbasis Fuzzy Logic Control, ELECTRICIAN - Jurnal Rekayasa dan Teknologi Elektro.

Sistem Pengaturan Kecepatan Motor DC Pada Alat Penyiram Tanaman Menggunakan Kontroler PID. Penelitian yang dilakukan oleh Ahmad Akhyar pada tahun 2014, bertujuan untuk membuat robot penyiram tanaman yang dapat berjalan. Kesimpulan dari penelitian tersebut yaitu: penelitian tersebut menggunakan sensor kelembaban yang dapat mengurangi jangkauan jarak karena terkendala kabel yang terhubung dari tanah ke robot.

Design and Implementation of IR based Line Follower Robot for Cooperative Task Sharing. Penelitian ini dilakukan oleh Pintu Dubey dan Alka Dubey pada tahun 2013. Tujuan dari penelitian ini adalah untuk mengembangkan robot yang dapat membagi tugasnya dengan bekerja sama menggunakan sensor IR, pada penelitian ini tugas tersebut ada balapan relay. Kesimpulan yang didapat adalah, robot yang didesain oleh Pintu dan Alka menunjukan bahwa robot dapat bekerjasama untuk menyelesaikan pekerjaannya.

\subsection{Definisi Robot}

Kata robot berasal dari bahasa Cek yaitu robota, yang berarti pekerja. Menurut arti bahasa, robot adalah sebuah alat mekanik yang dapat melakukan tugas fisik, baik menggunakan pengawasan dan kontrol manusia, atau menggunakan program yang telah didefinsikan terlebih dahulu. Sedangkan menurut Kamus Besar Bahasa Indonesia, robot adalah alat berupa orangorangan dan sebagainya yang dapat bergerak atau berbuat seperti manusia, dan dikendalikan oleh mesin. (Winarno, et al, 2011, p2)

Berdasarkan Cangelosi dan Schelsinger (2015, p19), Secara historis, Etimologi kata robot berasal dari kata slavia yaitu robota, yang digunakan untuk merujuk kepada budak atau pekerja paksa. Kata ini pertama kali muncul dalam drama R.U.R (Rossum Universal Robots), yang ditulis oleh Karel Capek. Etimologi ini menunjukan kalau robot di buat untuk membantu manusia dalam tugasnya sehari-hari, dan pada kasus tertentu untuk menggantikan manusia dengan melakukan tugas mereka pada industri robotika.

Kamus bahasa inggris Oxford menyatakan robot sebagai mesin yang mampu menjalankan aksi yang kompleks secara otomatis, terutama yang dapat di program menggunakan komputer. Definisi ini mengandung 4 konsep utama yang penting dalam mengembangkan robot, yaitu (Cangelosi, Schlesinger 2015, p19):

1. Mesin

2. Kompleks

3. Otomatis

4. Dapat di program dengan komputer

Berdasarkan Cook (2015, p2), Berdasarkan perspektif anatomi, bagian-bagian robot dapat di masukan kedalam beberapa kategori:

1. Otak

Robot bisa juga berfungsi tanpa menggunakan sebuah otak, contohnya adalah robot yang di kendalikan oleh manusia, sedangkan ada dua tipe untuk robot yang menggunakan otak, yaitu:

a. Mikroprossesor

Mikroprosessor adalah sirkuit terintegrasi yang didalamnya hanya terdapat CPU. Mikroposessor ini tidak memiliki RAM, ROM dan beberapa perangkat lainnya, sehingga seorang perancang sistem harus menambahkannya secara eksternal agar dapat bekerja dengan baik. Contohnya adalah chip prosessor buatan Intel dan AMD. Mikroprosessor ini melakukan pekerjaan yang tidak spesifik seperti bermain game, mengembangkan perangkat lunak, browsing, dan lain-lain.

b. Mikrokontroler

Mikrokontroler adalah sirkuit terintegrasi yang memiliki $C P U$ dan memiliki RAM, ROM, dan perangkat lainnya didalam sebuah chip. Mikrokontroller biasanya digunakan untuk melakukan pekerjaan yang spesifik, dimana pekerjaan yang akan dilakukan memiliki input dan output yang sudah ditentukan. Mikrokontroler bekerja pada kecepatan yang kecil yaitu $30 \mathrm{MHz}$ sampai dengan $50 \mathrm{MHz}$.

2. Tenaga Listrik

Pasokan tenaga listrik ini terdiri dari:

a. Sumber Tenaga

Robot secara umum paling banyak menggunakan sumber daya dari baterai. Tenaga matahari juga bisa menjadi pilihan untuk memasok daya ke robot. Pada robot yang canggih, tenaga matahari juga digunakan mengisi daya baterai pada kondisi cahaya yang optimal, dimana pada malam harinya robot dapat tetap bekerja dengan menggunakan baterai.

b. Regulasi Listrik

Bagian kecil dari robot yang di dedikasikan secara khusus untuk meningkatkan kestabilan kekuatan daya yang tersedia untuk perangkat elektronik. Alasan lainnya regulasi ini adalah karena beberapa perangkat robot membutuhkan lebih banyak tenaga dibandingkan perangkat yang lain.

c. Saklar On/Off

Saklar ini berfungsi untuk mematikan dan menghidupkan robot, sehingga robot dapat digunakan dan dimatikan jika tidak sedang diperlukan.

3. Sensor 
Berikut adalah beberapa jenis sensor, yaitu:

a. Tombol tekan,

b. Sensor cahaya,

c. Sensor infrared,

d. Baterai tester,

e. Saklar kemiringan,

f. Sensor suhu.

\section{Aksi dan Tanggapan}

Robot melakukan aksi dari hasil yang didapatkan oleh sensor. Contohnya adalah:

a. Gerakan,

b. Suara

c. Tampilan,

d. Indikasi Cahaya.

5. Tubuh

Semua bagian dari robot harus dihubungkan ke kerangka utama dari Robot. Kerangka utama inilah yang dapat melindungi bagian robot tersebut dari kerusakan.

a. Estetis

Aspek yang penting bagi tubuh adalah daya tarik. Tidak perduli seberapa bagusnya robot jika dilihat secara teknis, penampilan ini akan memberikan dampak yang besar terhadap bagaimana orang melihat robot tersebut.

\subsection{Robot Pemberi Pakan Ayam Ternak Otomatis}

Sesuai dengan namanya, line follower (LF) adalah robot yang dapat bergerak tanpa bantuan manusia, tetapi menggunakan panduan berupa garis. Prinsip dasar robot line follower adalah membedakan warna gelap dan terang pada lantai/dasar lapangan. Warna gelap dapat diartikan warna yang tidak dapat memantulkan cahaya, contohnya hitam. Sedangkan warna terang diartikan sebagai warna yang dapat memantulkan cayaha, contohnya putih. Perbedaan warna pada dasar permukaan tersebut menjadi acuan sebuah robot line follower untuk bergerak mengikuti garis yang telah ditentukan. Robot jenis ini memiliki dua kategori, yaitu line follower analog dan digital. Line follower analog adalah jenis robot pengikut garis yang tidak memerlukan pemrograman robot yang melibatkan software sedangkan line follower digital melibatkan software. (Winarno, 2011, p14).

\subsection{Sistem Dasar Robot}

Berdasarkan Winarno (2011, p14), untuk membuat sebuah robot, kita harus memahami sistem dasar yang bekerja pada robot tersebut. Sistem dasar ini dibuat dengan perencanaan yang tepat, agar robot yang dirancang dapat berfungsi dengan baik.

\section{a. Sistem Mekanik}

Sistem mekanik merupakan salah satu bagian penting yang digunakan untuk menyusun sebuah robot. Sistem mekanik meliputi bentuk dan desain robot, material penyusun robot, serta sistem penunjang penggerak robot. Beberapa material yang dapat digunakan sebagai penyusum robot antara lain acrylic, kayu triplek, PVC, dan plastik mainan anak-anak. Material penyusun robot merupakan unsur penting dalam menentukan bobot robot yang mempengaruhi kelincahan robot tersebut.

\section{b. Sistem Elektronik}

Sistem elektronik merupakan faktor utama sbuah robot. Sistem elektronik digunakan untuk menggerakkan, mengendalikan, dan menstabilkan robot. Secara umum, yang tergolong dalam sistem elektronik robot adalah rangkaian sensor, rangkaian catu daya, rangkaian pengendali (driver), rangkaian kontrol, dan rangkaian penggerak (aktuator).

Rangkaian sensor dapat dikatakan sebagai 'mata' sebuah robot untuk mengenali lingkungan sekitarnya. Rangkaian catu daya adalah rangkaian pembangkit listrik sebuah robot. Rangkaian ini berfungsi untuk memberi, mengatur, dan membagi daya listrik pada robot.

Rangkaian oengendali (driver) merupakan rangkaian yang berguna untuk mengendalikan beberapa rangkaian yang terdapat padaa robot. Rangkaian kontrol adalah sistem otak dari sebuah robot. Rangkaian ini berfungsi untuk mengontrol semua komponen yang ada pada sebuah robot.

Rangkaian penggerak biasa disebut dengan aktuator berfungsi untuk menggerakkan robot sesuai dengan perinah yang diberikan. Penggerak robot yang utama adalah motor. Jenis-jenis motor yang digunakan dapat disesuaikan dengan jenis robot yang ingin dibuat. Misalnya untuk lengan robot dapat menggunakan motor servo, dan untuk line follower dapat menggunakan motor DC.

\section{c. Sistem Pemrograman}

Sistem pemrograman digunakan pada pembuatan robot yang bersifat programmable, atau robot yang menggunakan IC mikrokontroler atau sistem kontrol lain sebagai otaknya. Robot yang menggunakan mikrokontroler memiliki rangkaian elektronik yang relatif lebih sederhana., karena sebagian elektronik telah digantikan oleh mikrokontroler itu sendiri. Gerak robot bergantung pada program yang disimpan dalam IC mikrokontroler. Sistem pemrograman yang biasa digunakan antara lain Bahasa C, Assembly, Basic, dan Pascal.

\subsection{Software Proteus 8}

Proteus adalah sebuah software untuk mendesain PCB yang juga dilengkapi dengan simulasi pspice pada level skematik sebelum rangkaian skematik diupgrade ke PCB (Falany dan Budi, 2015).

Proteus merupakan software yang dibuat oleh Labcenter Electronics, yang dapat digunakan untuk melakukan simulasi VSM, dan PCB. Pada saat ini proteus menyediakan hampir 800 variasi mikrokontroler yang langsung dapat di gunakan untuk simulasi. Beberapa fitur proteus, yaitu:

1. Simulasi VSM

2. Membuat desain PCB

3. Visual Desainer

\section{Metodologi Penelitian}

Metodologi pada penelitian ini, terdiri dari tahapan mendesain diagram blok, perencanaan, pembuatan, dan uji coba. 


\subsection{Diagram Blok Pembuatan Robot}

Tahap awal membuat sebuah robot adalah memdesain diagram blok, sehingga proses pengerjaan robot dapat diselesaikan dengan cepat, karena tahapan pembuatan robot sudah diketahuhi di awal dengan jelas.

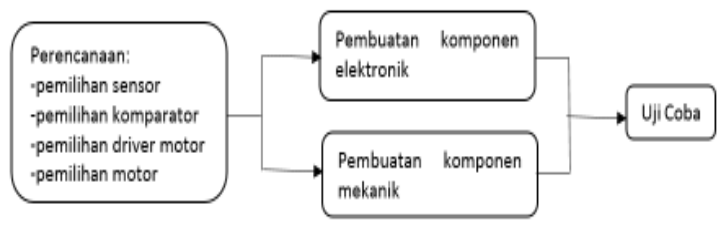

Sumber: Winarno (2011)

Gambar 1. Diagram Blok Proses Pembuatan Robot PPATO

\subsection{Perancangan Robot PPATO}

Tahap perencanaan meliputi hal-hal berikut, yaitu: pemilihan komponen elektronik dan mekanik, termasuk di dalamnya menentukan komponen sensor, komparator, driver motor, dan motor yang digunakan dalam membuat robot. Terkait dengan mendesain skema Robot PPATO menggunakan Software Proteus 8, pemilihan komponen ini dapat dikerjakan secara langsung pada software tersebut.

\subsection{Desain Robot PPATO}

Mendesain adalah tahap setelah memilih komponen elektronik yang dibutuhkan untuk membuat robot. Setelah memilih komponen, selanjutnya mendesain komponen atau merangkai atau merakit komponen-komponen tersebut pada lembar kerja dari Software Proteus 8 tersebut, seperti halnya merangkai komponen pada papan PCB (Printed Circuit Board).

\subsection{Uji Coba Robot PPATO}

Pada penelitian ini, uji coba dapat langsung dikerjakan pada Software Proteus 8 tersebut, setelah sebelumnya mengerjakan kompilasi dan tahapan lainnya, dengan cara menekan tombol icon Run. Jika rangkaian tersebut benar, maka hasil dari desain tersebut ada output atau keluaran, seperti roda motor berputar, lampu led menyala, buzzer bunyi, dan lain-lainnya.

\section{Hasil dan Analisa}

Untuk melihat hasil dan analisa dari penelitian ini, penulis menjelaskannya dalam sub bab Hasil dan Analisa, sebagai berikut ini:

\section{a. Diagram Blok Robot PPATO}

Untuk menghasil sebuah desain dari Robot PPATO, penulis menghasil dua hal berikut, yaitu: diagram blok Robot PPATO dan Desain Skema Robot PPATO, dapat dijelaskan secara detail sebagai berikut:

Tahap awal dalam membuat sebuah robot diawali dengan pembuatan diagram blok dari Robot PPATO tersebut, secara global dapat digambarkan sebagai berikut:

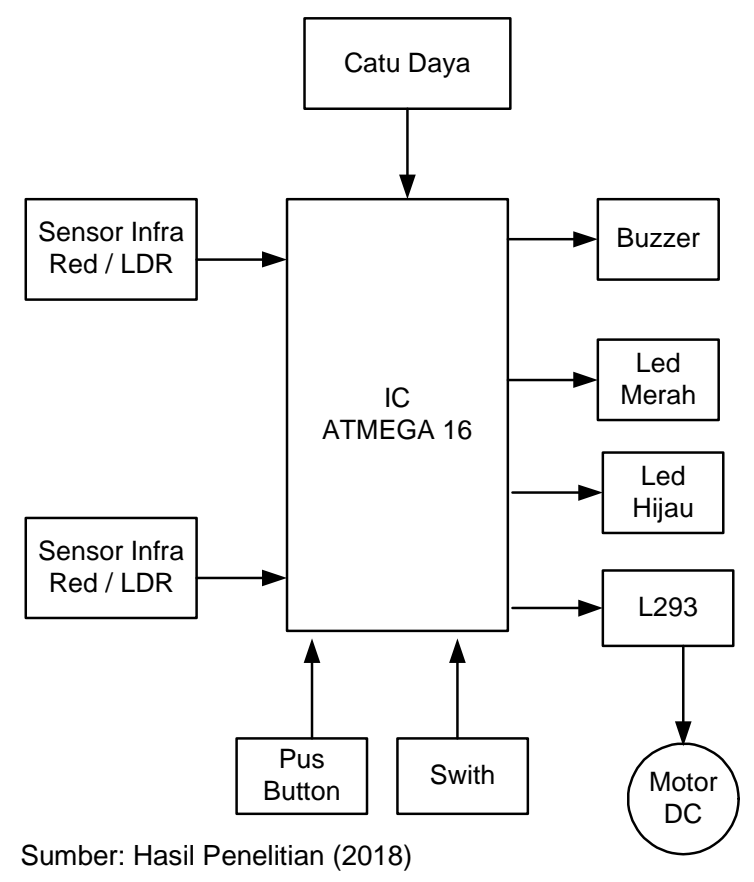

Gambar 2. Diagram Blok Robot PPATO

Secara garis besar cara kerja alat, sebagai berikut:

1. Bila sensor terhalang oleh pakan ternak maka kondisi output yang dihasilkan berlogika low (0) lalu masuk ke IC mikrokontroler untuk disesuaikan dengan data program yang telah dibuat, bila IC mikrokontroler mendapatkan kondisi keadaan yang berlogika (0) maka mikrokontroler akan mengeluarkan output pada komponen led hijau keadaan menyala. Lalu timer waktu untuk memberikan pakan ternak sudah tersimpan ke dalam IC mikrokontroler sebanyak 3 kali, sehingga IC mikrokontroler akan menggerakan driver motor DC untuk membuka penutup pakan ternak, agar pakan ternak keluar dan masuk kedalam tempat makan ternak, waktu yang di berikan untuk menutup kembali sebesar 1 menit, untuk memberhentikan putaran motor DC bila penutup pakan ternak menyentuh swtih, maka kondisi logika keadaan low yang artinya IC mikrokontroler akan memberhentikan putaran motor DC.

2. Bila sensor tidak terhalang dan memantulkan cahaya, maka IC Mikrokontroler akan menyalakan lampu led merah dan membunyikan buzzer menandakan pakan ternak dalam keadaan habis, sehingga di perlukan mengisi kembali pakan ternak kedalam tempatnya.

\section{b. Desain Skema Robot PPATO Dengan \\ Simulator Software Proteus 8}

Desain Robot PPATO dibuat dengan menggunakan software Proteus 8. Pada perancangan ini dilakukan simulasi pemasangan alat pada mikrokontroler ATmega32A. Berikut adalah gambar rangkaian Robot Pemberi Pakan Ayam Ternak Otomatis atau Robot PPATO. 


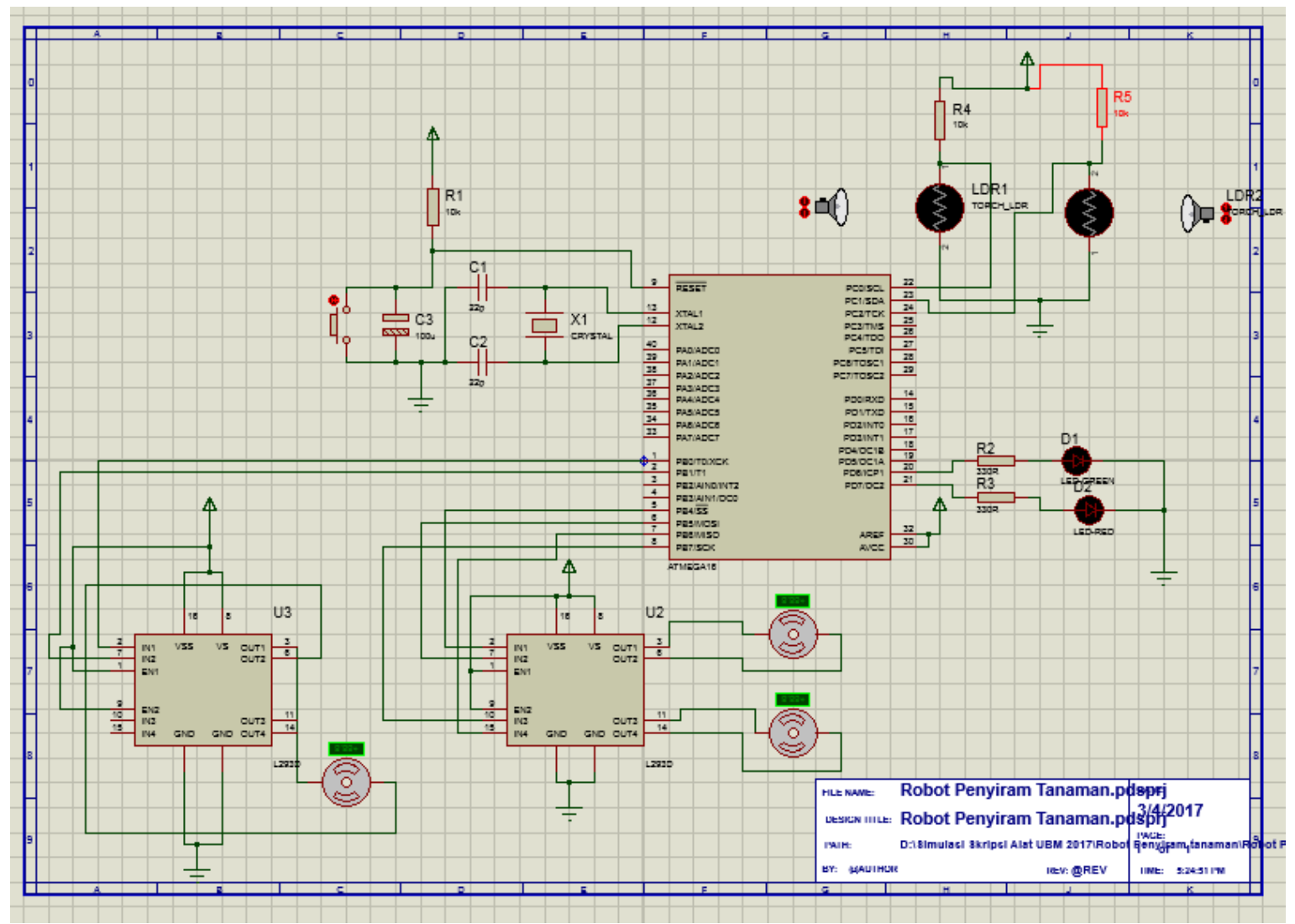

Sumber: Hasil Penelitian (2018)

Gambar 3. Disain Robot Pemberi Pakan Ayam Ternak Otomatis

\section{c. Coding C Robot PPATO}

\#include <mega16.h>

\#include <delay.h>

void main(void)

$\{$ PORTA $=0 \times 00$;

$\mathrm{DDRA}=0 \times 0 \mathrm{ff} ;$

$\mathrm{PORTB}=0 \times 00$;

$\mathrm{DDRB}=0 \times 0 \mathrm{ff} ;$

$\mathrm{PORTC}=0 \times 00$;

$\mathrm{DDRC}=0 \times 00$;

PORTD $=0 \times 00$;

DDRD $=0 \times 00$;

while (1)

$\{$ PORTA $=0 \mathrm{~b} 00000010$;

delay_ms(300);

PORTB. $6=0$;

PORTB. $7=0$;

delay_ms(200);

PORTB. $6=1$;

PORTB. $7=0$;

delay_ms $(1000)$;

PORTB. $6=0$;

PORTB. $7=0$;

delay_ms(500);

PORTB. $6=0$;

PORTB. $7=1$;

delay_ms (1000);

PORTB. $6=0$;

PORTB. $7=0$; delay_ms(300);

PORTA $=0 \mathrm{~b} 00000000$;

delay_ms(500);

PORTA $=0 \mathrm{~b} 00000001$;

delay ms(400);

\}$;\}$

\subsection{Analisa}

\section{a. Analisa Komponen Robot PPATO}

Tabel 1. Komponen Robot PPATO

\begin{tabular}{|c|l|c|}
\hline No. & \multicolumn{1}{|c|}{ Nama Komponen } & Banyaknya \\
\hline 1. & $\begin{array}{l}\text { IC Mikrokontroler ATMEGA } \\
16\end{array}$ & 1 Buah \\
\hline 2. & IC Driver L293 & 1 Buah \\
\hline 3. & Soket IC 40 Pin & 1 Buah \\
\hline 4. & Soket IC 16 Pin & 1 Buah \\
\hline 5. & IC Regulator 7805 & 1 Buah \\
\hline 6. & IC Regulator 7812 & 1 Buah \\
\hline 7. & Travo 1 Amper & 1 Buah \\
\hline 8. & Sensor Infra red / LDR & 2 Pasang \\
\hline 9. & IC OMP LM 324 (penguat) & 1 Buah \\
\hline 10 & Resistor 330 $\Omega$ & 6 Buah \\
\hline 11. & Resistor 10K $\Omega$ & 6 Buah \\
\hline 12. & Dioda 1 A & 1 Buah \\
\hline 13. & Led merah , Led Hijau, Led & B Buah \\
\hline
\end{tabular}




\begin{tabular}{|c|c|c|}
\hline 14. & Pus Button & 1 Buah \\
\hline 15. & $\begin{array}{l}\text { Kapasitor (elco) } \\
16 \mathrm{v} / 1000 \mathrm{mf}\end{array}$ & 2 Buah \\
\hline 16. & Kapasitor (elco) 16v/100mf & 2 Buah \\
\hline 17. & Kristal $12 \mathrm{MHZ}$ & 1 Buah \\
\hline 18. & Kabel Pelangi & $\begin{array}{l}2 \text { Gulung } \\
\text { /meter }\end{array}$ \\
\hline 19. & Conektor (tulang Ikan) & 4 Buah \\
\hline 20. & Conektor Putih 2 Pin & 3 Buah \\
\hline 21. & Conektor Putih 4 Pin & 4 Buah \\
\hline 22. & Swith & 3 Buah \\
\hline 23. & Motor DC & 1 Buah \\
\hline 24. & Papan PCB & $\begin{array}{c}\text { 1lembar }(20 \mathrm{~cm} \\
\times 20 \mathrm{~cm})\end{array}$ \\
\hline 25. & Timah Solder & $1 \mathrm{Rol}$ \\
\hline 26. & Larutan PCB Flerit Clorit & $1 / 4 \mathrm{Kg}$ \\
\hline 27. & Colokan Listrik & 1 Buah \\
\hline 28. & Box / Kotak Pakan ternak & $1 / 2$ Lembar \\
\hline 29. & Buzzer & 1 Buah \\
\hline 30. & Transistor A733 & 1 Buah \\
\hline 31. & Resistor 2k2 & 1 Buah \\
\hline 32. & Resistor $47 \Omega$ & 1 Buah \\
\hline
\end{tabular}

Sumber: Hasil Penelitian (2018)

\section{b. Analisa Logika Robot PPATO}

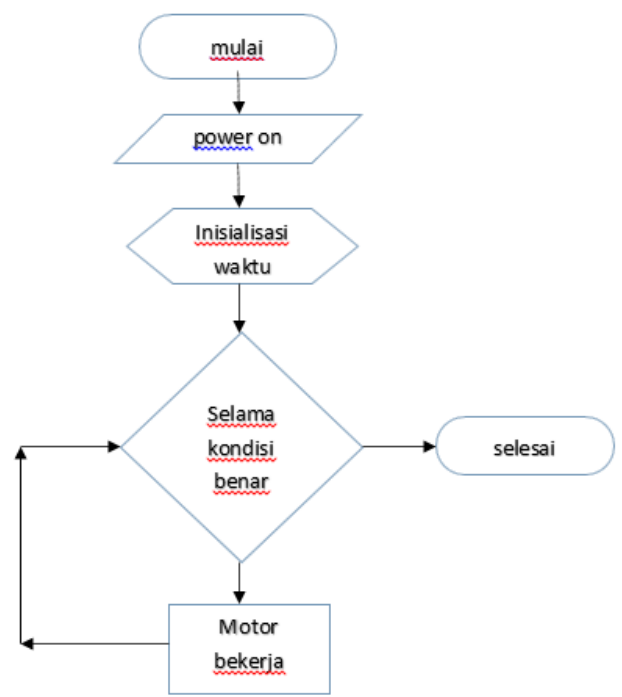

Sumber: Hasil Penelitian (2018)

Gambar 4. Flowchart Robot Pemberi Pakan Ayam Ternak Otomatis

Cara kerja robot yang dijelaskan dengan flowchart di atas adalah ketika Power On, maka program yang sudah di atur sebelumnya akan menunggu jam pada RTC, jika sudah sesuai maka akan melihat kondisi timer apakah pada kondisi timer, jika telah sesuai dengan timer maka motor akan bekerja yang nantinya akan menggerakkan tempat penampungan makanan, untuk melakukan pengisian makanan. Sementara bila sensor tidak terhalang dan memantulkan cahaya, maka IC Mikrokontroler akan menyalakan lampu led merah dan membunyikan buzzer menandakan pakan ternak dalam keadaan habis, sehingga di perlukan mengisi kembali pakan ternak kedalam tempatnya.

\subsection{Kesimpulan}

Robot Pemberi Pakan Ayam Ternak Otomatis atau yang selanjutkanya akan disingkat menjadi Robot PPATO, tujuannya untuk melakukan pekerjaan rutin memberi pakan pada ayam ternak sacara otomatis pada waktu tertentu yang terjadwal. Karakteristik Robot PPATO yaitu robot akan memberikan pakan pada ayam ternak pada waktu tertentu terjadwal, dengan bantuan komponen elektronika utama yaiut: IC Timer, Driver Motor DC, Sensor Infra Red atau LDR, dan buzzer yang dipasang pada mesin robot.

Cara kerja robot, dimulai ketika Power On, maka program yang sudah di atur sebelumnya akan menunggu jam pada RTC, jika sudah sesuai maka akan melihat kondisi timer apakah pada kondisi timer, jika telah sesuai dengan timer maka motor akan bekerja yang nantinya akan menggerakkan tempat penampungan makanan, untuk melakukan pengisian makanan. Bila sensor tidak terhalang dan memantulkan cahaya, maka IC Mikrokontroler akan menyalakan lampu led merah dan membunyikan buzzer menandakan pakan ternak dalam keadaan habis, sehingga di perlukan mengisi kembali pakan ternak kedalam tempatnya.

Simulator Software Proteus 8 dapat dimanfaatkan sebelum pembuatan robot secara hardware, kebutuhan dan pengujian komponen dapat dlakukan sebelum pembuatan robot secara real, sehingga menjadi lebih efektif dan efisien dari segi waktu, tenaga, dan biaya. Hal ini, karena sebelum pemilihan dan pembelian komponen sudah di uji coba terlebih dahulu dengan menggunakan simulator tersebut. Kesalahan pemilihan dan pembelian komponen dapat dihindari atau teratasi sebelumnya.

\subsection{Saran}

Untuk pembuatan robot secara real, sebaiknya untuk selalu melakukan desainnya dengan menggunakan alat bantu berupa simulator Software Proteus 8, untuk lebih efektif dan efisien dari segi waktu, tenaga, dan biaya serta lebih kreatif lagi dalam mendesain dan pemilihan komponenkomponennya, bahkan memilih komponen yang lebih murah dan tentunya lebih tepat. Jenis-jenis robot lainnya seperti Robot Pemindah Barang, Robot Line Follower Penyiram Tanaman, dan lainlain dapat dirancang dan disimulasikan dengan menggunakan simulator Software Proteus 8 . Selamat berkreasi dan berkreativitas.

Hasil desain dari skema Robot PTO tersebut, adalah hanya salah satu dari sekian desain skema robot yang dapat dibuat, desain lain sangat memungkin untuk dibuat dan dengan logika yang berbeda juga, begitu pula halnya dengan komponen atau logika programnya.

\section{DAFTAR PUSTAKA}

1. Achmad Zakki Falani dan Setyawan Budi. (2015). Robot Line Follower Berbasis Mikrokontroler Atmega 16 dengan 
Menampilkan Status Gerak Pada LCD. Narodroid: Vol.1. No.1.

2. Akhyar, A. (2014). Sistem Pengaturan Kecepatan Motor DC Pada Alat Penyiraman Tanaman Menggunakan Kontroler PID, Teknik Elektro Universitas Brawijaya, Vol.2. No.4.

3. Cangelosi, A. dan Schlesinger Matthew. (2015). Developmental Robotics: From Babies to Robots. The MIT Press, London.

4. Cook, David. (2015). Robot Building for Beginners: Third Edition. Apress. California.

5. Nawali, Erixon D., etc. Rancang Bangun Alat Penguras Dan Pengisi Tempat Minum Ternak Ayam Berbasis Mikrokontroler Atmega 16. Jurnal Teknik Elektro dan Komputer. Ejournal.unsurat.aac.id. ISSN: 2301-8402.

6. Pintu Dubey dan Alka Dubey. (2013). Design and Implementation of IR based Line Follower for Cooperative Task Sharing. E-Journal of Science \& Technology. Vol.8. No.3.

7. Ridhamuttaqin, Aji. Rancang Bangun Model Sistem Pemberi Pakan Ayam Otomatis
Berbasis Fuzzy Logic Control, ELECTRICIAN - Jurnal Rekayasa dan Teknologi Elektro.

8. Winarno dan Arifianto Deni. (2011). BIKIN ROBOT ITU GAMPANG. Jakarta: Penerbit PT Kawan Pustaka. 